\title{
Three-Dimensional Reconstruction of Columna Vertebralis Images of Elite Male Weightlifters Taken by a Multi-Detector Computerized Tomography (MDCT)
}

\author{
Reconstrucción Tridimensional de Imágenes de Columna Vertebral de \\ Pesistas de Elite por Tomografía Computadorizada Multidetectora
}

\author{
Alparslan Ince* \& Emrullah Eken ${ }^{* *}$
}

INCE, A. \& EKEN, E. Three-dimensional reconstruction of columna vertebralis 1mages of elite male weightlifters taken by a multidetector computerized tomography (MDCT). Int. J. Morphol., 32(4):1184-1189, 2014.

SUMMARY: This study aims to carry out a comparative study on the vertebral structure of the elite male weightlifters and the sedentary group (control group) by obtaining three-dimensional data and models by means of photogrammetry from the columna vertebralis sections taken by MDCT. The columna vertebralis of the 8 male weightlifters and 8 sedentary individuals (control group) was scanned with a high-definition diagnostic MDCT device during the study. The demographic findings suggest no difference in both the weightlifters and the sedentary individual. The 2D axial images in DICOM format were burnt on CDs and then copied on a PC on which 3D-Doctor 4.0 , which is a 3D modelling program had already been installed. The reconstruction was carried out with the 3D rendering component of the program. All the data were automatically measured by the abovementioned program and the statistical analyses were determined with a $-\mathrm{t}$ test by SPSS 15. Considering the statistical results of the Columna vertebralis, only in the length of Pars lumbaris some statistically considerable differences $(\mathrm{p}<0.05)$ were observed between the vertebras L3-L5 in the elite male weightlifters and the sedentary individuals. Therefore, concluding from the idea that these techniques and the three-dimensional reconstruction procedures should be put into practice in the field of sports medicine, the substructure works that will be carried out on weightlifters by means of MDCT are thought to be supported by these studies.

KEY WORDS: Columna vertebralis; Three-dimensional reconstruction; Elite weightlifters; Computerized tomography.

\section{INTRODUCTION}

Technical developments and the use of anatomical knowledge in clinical practices have brought forth a new dimension on the diagnosis and treatment of diseases in columna vertebralis. It is the instructions in which national and international codes of ethics are gradually being employed that have led us to study in this scope. In this respect, bringing to foreground the scientific data employed both in training and academic studies and reducing the use of cadavers are thought to be what anatomists should not ignore. MDCT is an effective diagnostic modality that produces two-dimensional (2D) multiplanar images (horizontal, coronal, sagittal, axial, oblique etc.) of the anatomical structure and deformities of bones (Hall, 1994). Cross-sectional knowledge of anatomy is a must to make an efficient use of MDCT.MDCT, which is a recent technological device, produces hundreds of multiplanar $2 \mathrm{D}$ images in seconds. The images obtained are then converted into 3-D images by means of sophisticated computer programs
(Hu et al., 2000). 3-D geometrical modelling technique has a wide range of practice in the field of medical training along with the practices in plastic surgery, orthopaedics, traumatology and neurosurgery (Krupa et al., 2004).

Literary review reveals that there have been conducted a limited number of biomechanical studies while there have been a great number of biochemical, hematologic and neurologic studies carried out on weightlifters (Marchocka \& Smuk, 1984; Hoek van Dijke et al., 1999; Harbili \& Aritan, 2005).

Moreover, no studies on the detailed analysis of the Computerized Tomography (CT) images of columna vertebralis in weightlifters and 3-D reconstruction of columna vertebralis images have been encountered by means of the literary review. Therefore, this study aims to do a

\footnotetext{
* Physical Education and Sport in Schools, Ordu University, Ordu, Turkey.

** Faculty of Veterinary Medicine, Department of Anatomy, Selcuk University in Konya, Turkey.
} 
comparative study on the cervical, thoracal, lumbal and sacral regions of the columna vertebralis of the both groups by reconstructing the 3D structure of the columna vertebralis images taken from both the elite weightlifters and the control group by MDCT.

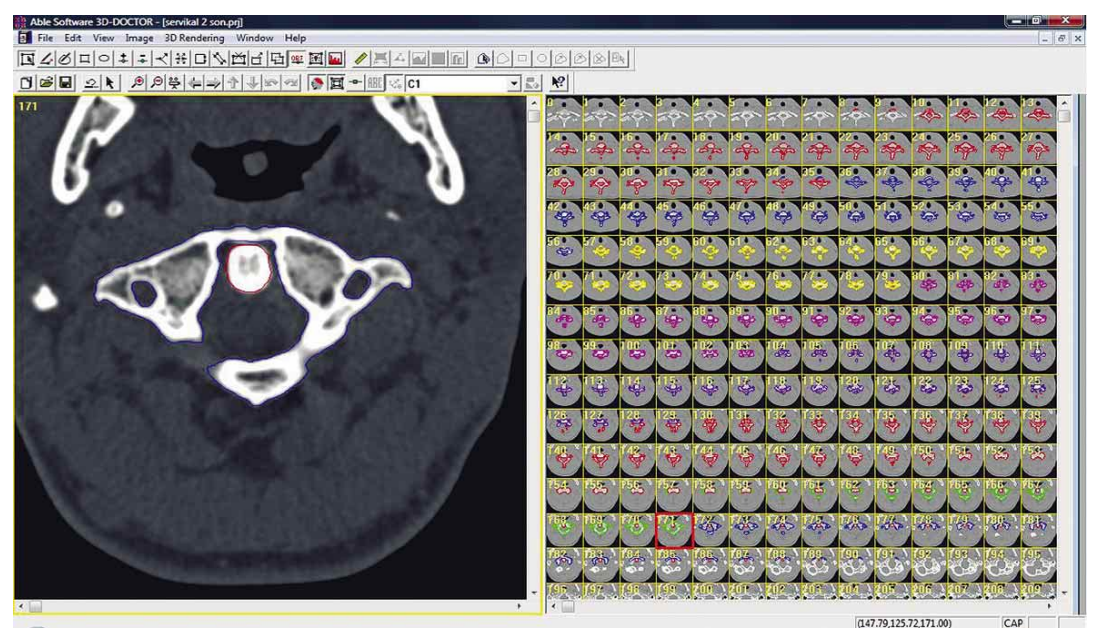

Fig. 1. Manually checked and fixed bone boundaries.

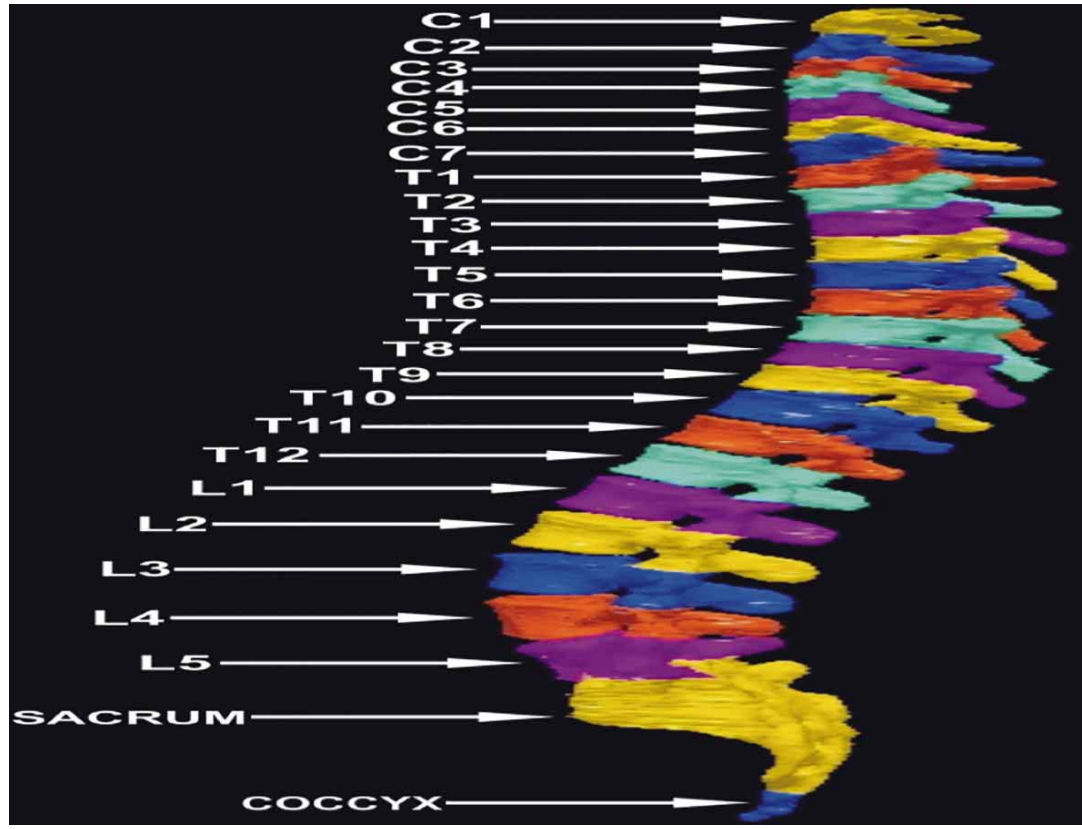

Fig. 2. 3D Reconstruction view of columna vertebralis.

\section{MATERIAL AND METHOD}

The columna vertebralis of 8 elite weightlifters and 8 sedentary individuals (control group) were scanned by the high-definition diagnostic MDCT device (Somatom Sensation 64; Siemens Medical Solutions, Forchheim, Germany) during the study.
Parameters of MDCT device were set as follows: i) physical detector collimation: $32 \times 0.6 \mathrm{~mm}$, ii) ultimate section collimation: $64 \times 0.6 \mathrm{~mm}$, iii)section thickness: $0.75 \mathrm{~mm}$, iv) gantry rotation time: $330 \mathrm{msec}, \mathrm{v}) \mathrm{kVp}: 120$, vi) $\mathrm{mA}: 300$, vii) resolution: $512 \times 512$ pixel and viii) resolution range: $0.92 \times 0.92$.

The relevant bone parts were added to the geometrical models. Dose parameters were set and the scanning was carried out based on the Standard protocols and literature reviews (Prokop, 2003; Kalra et al., 2004). Both groups were scanned when they lay supine. The 2D axial images taken by the MDCT device were then copied in DICOM format on CDs. Afterwards, those images were copied on a PC where 3D-Doctor 4.0 (Copyright $@$ 1998-2010 Able Software Corp)- a 3D modeling program was already installed. The segmentation process was based on the procedures of the study carried out by Bazille et al. (1994). The process of segmentation carried out was called semi-segmentation. The manual setting process for each section took 5-6 minutes. Bone boundaries were automatically configured in the first phase of the semiautomatic segmentation process.

After the process of the automatic boundary segmentation, dots not positioned right on the bone images were manually aligned dot by dot with the mouse by means of the interactive boundary editing routine (Fig. 1). After manual checking, all the aligned boundaries of the bone surfaces were arranged in a way that each boundary overlapped one another. The reconstructions were carried out by means of the $3 \mathrm{D}$ rendering component of the program (Fig. 2). The volume, surface area and length of the vertebrae which compose the columna vertebralis and canalis vertebralis were automatically measured by means of the 3D program. Afterwards, the percentage of the relevant values of each vertebra (except for sacrum and coccyx vertebrae) in proportion to 
each vertebra was measured and the statistics regarding these proportions were analyzed. Only the numerical values of the measurements regarding Sacrum and coccyx vertebrae were provided. Since the percentage of these two vertebrae was impossible to calculate as there exists a complete fusion between them, they were not included in the statistics. Statistical analysis was established with a t-test on SPSS 15.0 (SPPS Inc. Corp, Chiago, IL, USA) and the statistical significance was noted as $\mathrm{p}<0.05$.

\section{RESULTS}

No considerable difference in terms of height (171.87 $\pm 2.34,170.00 \pm 2)$, weight $(82.37 \pm 4.12,76.62 \pm 1.53)$ and age $(21.12 \pm 0.44,22.25 \pm 0.36)$ was observed in the weightlifters and sedentary individuals. The 3-D images of the columna vertebralis reveal that there are 7 cervical, 12 thoracal, 5 lumbal, 5 sacral and 4 coccygeal vertebrae adding up to 33 vertebrae in total (Fig. 2).

The statistical analysis of the biometrical values of the three-dimensionally reconstructed bones of the elite weightlifters and sedentary individuals. Considering the statistical results of the columna vertebralis in the elite weightlifters and sedentary individuals, statistically significant differences $(\mathrm{p}<0.05)$ in the length of only pars lumbaris were observed between the bones L3 and L5 (Table I). As there exists a fusion in the vertebrae which form Sacrum and Coccyx, rendering it impossible to reconstruct on a vertebra level, these two vertebrae were reconstructed as one bone.

Considering the segments of Canalis vertebralis, each segment was observed to have geometrical shapes that resemble a funnel and a cone (Figs. 3 and 4).

The biometrical values of the segments obtained by reconstruction were statistically analysed. Considering the statistical results of the canalis vertebralis, statistically significant differences $(\mathrm{p}<0.05)$ were observed between the elite weightlifters and sedentary individuals in the segments of pars cervicalis in terms of volume; in C7 segment in terms of surface area; in C5, C6 and C7 segment in terms of length. Statistically significant differences $(\mathrm{p}<0.05)$ were observed in pars thoracalis in T2, T7 ve T8 segments in terms of volume and in T4, T7 and T8 segments in terms of length.

Table I. The statistical analysis of vertebrae in the columna vertebralis considering the percentage values in terms of the volume, surface area and length mean (Mean \pm SD).

\begin{tabular}{lcccccc}
\hline Col. & \multicolumn{2}{c}{ Volume $\left(\mathbf{m m}^{\mathbf{2}}\right)$ \% } & \multicolumn{2}{c}{ Surface Area $\left(\mathbf{m m}^{\mathbf{2}}\right)$ \% } & \multicolumn{2}{c}{ Length $(\mathbf{m m}) \boldsymbol{\%}$} \\
\cline { 2 - 7 } Vert. & Weightlifter & Sedentary & Weightlifter & Sedentary & Weightlifter & Sedentary \\
\hline C1 & $14.1 \pm 2.2$ & $14.0 \pm 1.7$ & $15.5 \pm 1.8$ & $15.4 \pm 2.6$ & $16.1 \pm 1.1$ & $16.5 \pm 1.0$ \\
C2 & $17.9 \pm 1.0$ & $17.7 \pm 1.9$ & $16.4 \pm 0.5$ & $15.6 \pm 0.8$ & $16.4 \pm 0.9$ & $16.4 \pm 0.9$ \\
C3 & $11.7 \pm 0.5$ & $11.6 \pm 0.7$ & $11.4 \pm 1.4$ & $11.2 \pm 1.3$ & $14.4 \pm 0.5$ & $13.8 \pm 0.9$ \\
C4 & $12.3 \pm 0.6$ & $11.8 \pm 0.7$ & $11.9 \pm 0.7$ & $11.6 \pm 1.4$ & $13.5 \pm 0.7$ & $13.0 \pm 0.3$ \\
C5 & $13.0 \pm 0.8$ & $13.0 \pm 0.7$ & $13.7 \pm 0.5$ & $14.3 \pm 1.1$ & $13.7 \pm 0.8$ & $13.7 \pm 1.1$ \\
C6 & $14.4 \pm 0.8$ & $14.3 \pm 1.2$ & $14.6 \pm 0.3$ & $14.8 \pm 0.4$ & $12.7 \pm 0.5$ & $12.8 \pm 0.6$ \\
C7 & $16.7 \pm 1.9$ & $17.5 \pm 2.3$ & $16.5 \pm 1.2$ & $17.0 \pm 0.9$ & $13.2 \pm 0.8$ & $13.8 \pm 1.1$ \\
T1 & $6.3 \pm 0.9$ & $5.7 \pm 0.8$ & $7.5 \pm 1.2$ & $8.4 \pm 1.2$ & $7.3 \pm 0.5$ & $7.5 \pm 0.4$ \\
T2 & $6.2 \pm 0.3$ & $5.7 \pm 1.2$ & $7.2 \pm 0.8$ & $7.1 \pm 2.1$ & $7.9 \pm 0.8$ & $7.5 \pm 0.6$ \\
T3 & $6.3 \pm 0.3$ & $5.6 \pm 1.4$ & $6.9 \pm 0.3$ & $7.6 \pm 0.5$ & $7.9 \pm 0.3$ & $7.8 \pm 0.3$ \\
T4 & $7.1 \pm 0.2$ & $7.6 \pm 0.5$ & $7.6 \pm 0.3$ & $7.6 \pm 0.3$ & $8.1 \pm 0.5$ & $8.1 \pm 0.2$ \\
T5 & $7.3 \pm 0.5$ & $7.2 \pm 0.9$ & $8.0 \pm 1.0$ & $8.2 \pm 0.6$ & $8.0 \pm 0.4$ & $8.0 \pm 0.4$ \\
T6 & $7.6 \pm 0.3$ & $9.2 \pm 2.1$ & $8.1 \pm 0.2$ & $8.6 \pm 1.1$ & $8.1 \pm 0.3$ & $8.3 \pm 0.4$ \\
T7 & $8.2 \pm 0.4$ & $9.6 \pm 1.6$ & $9.0 \pm 1.2$ & $8.3 \pm 1.1$ & $8.1 \pm 0.4$ & $8.2 \pm 0.4$ \\
T8 & $8.6 \pm 0.5$ & $8.6 \pm 0.7$ & $8.5 \pm 0.3$ & $8.3 \pm 0.5$ & $7.7 \pm 0.4$ & $8.0 \pm 0.4$ \\
T9 & $9.4 \pm 0.3$ & $9.5 \pm 0.3$ & $8.6 \pm 0.6$ & $8.2 \pm 0.4$ & $8.6 \pm 0.2$ & $8.6 \pm 0.2$ \\
T10 & $10.4 \pm 0.7$ & $9.9 \pm 0.9$ & $9.6 \pm 1.2$ & $8.8 \pm 1.1$ & $9.0 \pm 0.2$ & $9.0 \pm 0.2$ \\
T11 & $10.7 \pm 0.6$ & $9.8 \pm 0.8$ & $9.3 \pm 1.3$ & $9.3 \pm 1.2$ & $9.1 \pm 0.4$ & $9.1 \pm 0.3$ \\
T12 & $11.9 \pm 0.8$ & $11.8 \pm 0.9$ & $9.7 \pm 0.8$ & $9.7 \pm 2.3$ & $10.3 \pm 0.3$ & $10.0 \pm 0.5$ \\
L1 & $18.0 \pm 1.2$ & $18.7 \pm 2.4$ & $18.4 \pm 1.0$ & $18.6 \pm 2.7$ & $18.8 \pm 0.3$ & $19.1 \pm 0.2$ \\
L2 & $19.5 \pm 0.8$ & $19.9 \pm 0.7$ & $19.4 \pm 1.7$ & $19.1 \pm 2.9$ & $19.9 \pm 0.6$ & $19.5 \pm 0.6$ \\
L3 & $21.0 \pm 0.9$ & $21.8 \pm 3.2$ & $23.4 \pm 0.6$ & $22.0 \pm 2.6$ & $21.8 \pm 0.4 *$ & $20.2 \pm 0.6 *$ \\
L4 & $20.5 \pm 1.3$ & $20.8 \pm 1.0$ & $20.7 \pm 2.1$ & $21.2 \pm 3.8$ & $20.5 \pm 1.0$ & $20.3 \pm 0.5$ \\
L5 & $21.1 \pm 2.4$ & $18.7 \pm 4.7$ & $18.1 \pm 1.5$ & $19.1 \pm 6.3$ & $19.0 \pm 1.0 *$ & $20.9 \pm 0.4 *$ \\
\hline
\end{tabular}

$* \mathrm{p}<0.05$ denotes the significance of mean between different groups on the same line. 
In addition, statistically significant differences $(\mathrm{p}<0.05)$ were observed in pars lumbalis in L5 segment in terms of volume, in L2, L3 and L5 segments in terms of surface area, in L3 and L5 segments in terms of length (Tabla II).

As there exists a fusion in the segments forming Sacrum and coccyx, each vertebra could not be reconstructed separately. Hence, the relevant segments were considered as a whole and duly reconstructed.

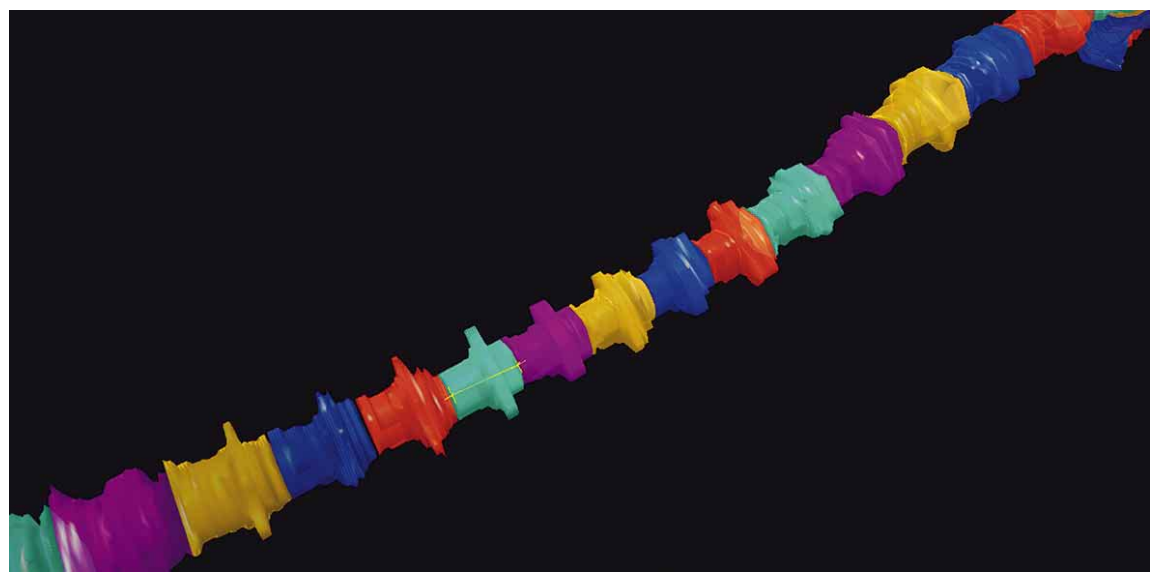

Fig. 3. 3D reconstruction of canalis vertebralis.

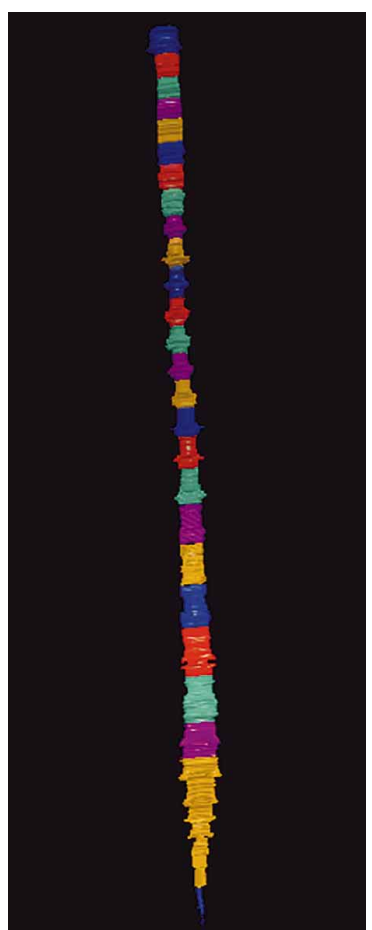

Fig. 4. 3D reconstruction of canalis vertebralis.

Table II. The statistical analysis of vertebrae in the canalis vertebralis considering the percentage values in terms of the $3 \mathrm{D}$ volume, surface area and length mean (Mean $\pm \mathrm{SD})$.

\begin{tabular}{lcccccc}
\hline Can. & \multicolumn{2}{c}{ Volume $\left(\mathbf{m m}^{2}\right) \%$} & \multicolumn{2}{c}{ Surface Area $(\mathbf{m m})$ \% } & \multicolumn{2}{c}{ Length $(\mathbf{m m}) \%$} \\
\cline { 2 - 6 } Vert. & Weightlifter & Sedentary & Weightlifter & Sedentary & Weightlifter & Sedentary \\
\hline C1 & $24.5 \pm 3.0$ & $25.6 \pm 3.3$ & $19.8 \pm 1.7$ & $19.4 \pm 1.8$ & $18.3 \pm 1.6$ & $18.1 \pm 0.6$ \\
C2 & $15.2 \pm 2.7$ & $13.8 \pm 1.5$ & $14.5 \pm 1.2$ & $13.1 \pm 1.4$ & $13.7 \pm 2.0$ & $13.4 \pm 1.3$ \\
C3 & $11.5 \pm 0.9$ & $10.9 \pm 0.4$ & $12.1 \pm 1.4$ & $12.3 \pm 0.9$ & $12.9 \pm 1.0$ & $12.6 \pm 0.6$ \\
C4 & $12.0 \pm 0.6$ & $10.9 \pm 0.8$ & $11.9 \pm 0.7$ & $12.3 \pm 1.1$ & $13.5 \pm 0.6$ & $12.7 \pm 0.8$ \\
C5 & $11.9 \pm 0.8$ & $10.6 \pm 0.5$ & $13.1 \pm 0.4^{*}$ & $12.1 \pm 0.4^{*}$ & $14.1 \pm 0.6$ & $13.0 \pm 0.7$ \\
C6 & $12.7 \pm 1.1$ & $11.5 \pm 1.8$ & $13.9 \pm 0.9^{*}$ & $12.0 \pm 0.5^{*}$ & $13.9 \pm 0.7$ & $13.3 \pm 0.4$ \\
C7 & $12.1 \pm 1.1^{*}$ & $16.5 \pm 1.9^{*}$ & $14.6 \pm 1.5^{*}$ & $19.0 \pm 1.4^{*}$ & $13.6 \pm 1.7^{*}$ & $17.0 \pm 0.5^{*}$ \\
T1 & $7.2 \pm 0.8$ & $5.9 \pm 0.4$ & $7.8 \pm 0.6$ & $7.4 \pm 1.4$ & $7.2 \pm 0.7$ & $7.0 \pm 0.8$ \\
T2 & $6.3 \pm 0.5^{*}$ & $4.9 \pm 0.6^{*}$ & $7.0 \pm 0.5$ & $6.7 \pm 0.5$ & $7.2 \pm 0.5$ & $6.8 \pm 0.5$ \\
T3 & $6.5 \pm 0.5$ & $6.5 \pm 0.4$ & $7.2 \pm 0.6$ & $6.9 \pm 0.4$ & $8.0 \pm 0.2$ & $7.4 \pm 0.4$ \\
T4 & $6.6 \pm 0.5$ & $6.7 \pm 0.3$ & $7.2 \pm 0.5$ & $6.6 \pm 0.4$ & $8.4 \pm 0.3^{*}$ & $7.5 \pm 0.2^{*}$ \\
T5 & $6.8 \pm 0.6$ & $6.5 \pm 0.7$ & $6.9 \pm 0.7$ & $6.8 \pm 0.7$ & $8.1 \pm 0.2$ & $8.0 \pm 0.3$ \\
T6 & $7.9 \pm 0.4$ & $8.2 \pm 0.5$ & $6.7 \pm 2.5$ & $7.6 \pm 0.6$ & $8.7 \pm 0.3$ & $8.3 \pm 0.4$ \\
T7 & $7.5 \pm 0.9^{*}$ & $9.6 \pm 0.8^{*}$ & $7.7 \pm 0.6$ & $7.6 \pm 0.2$ & $6.4 \pm 0.4^{*}$ & $8.3 \pm 0.3^{*}$ \\
T8 & $7.0 \pm 0.4^{*}$ & $8.7 \pm 0.6^{*}$ & $7.6 \pm 0.5$ & $7.6 \pm 0.3$ & $6.7 \pm 0.5^{*}$ & $8.1 \pm 0.2^{*}$ \\
T9 & $9.1 \pm 0.5$ & $8.9 \pm 0.6$ & $9.0 \pm 0.6$ & $8.3 \pm 0.7$ & $9.7 \pm 0.5$ & $8.8 \pm 0.5$ \\
T10 & $9.7 \pm 1.0$ & $8.5 \pm 0.6$ & $9.5 \pm 0.6$ & $9.8 \pm 1.7$ & $9.3 \pm 0.5$ & $9.4 \pm 0.6$ \\
T11 & $11.6 \pm 0.9$ & $12.2 \pm 0.7$ & $11.5 \pm 1.0$ & $12.4 \pm 1.0$ & $10.9 \pm 0.7$ & $9.7 \pm 0.3$ \\
T12 & $13.7 \pm 0.8$ & $13.2 \pm 0.5$ & $11.8 \pm 1.3$ & $12.5 \pm 0.5$ & $9.6 \pm 0.7$ & $10.8 \pm 0.8$ \\
L1 & $20.0 \pm 3.8$ & $17.8 \pm 0.9$ & $19.4 \pm 1.7$ & $18.8 \pm 1.4$ & $21.7 \pm 2.0$ & $19.7 \pm 0.5$ \\
L2 & $20.7 \pm 2.1$ & $18.1 \pm 2.4$ & $20.3 \pm 0.6^{*}$ & $18.4 \pm 0.8^{*}$ & $21.6 \pm 0.5$ & $21.6 \pm 0.9$ \\
L3 & $21.9 \pm 3.6$ & $22.3 \pm 1.5$ & $23.7 \pm 1.4^{*}$ & $20.2 \pm 1.2^{*}$ & $21.1 \pm 0.6^{*}$ & $18.7 \pm 0.6^{*}$ \\
L4 & $19.8 \pm 1.5$ & $21.2 \pm 2.8$ & $19.7 \pm 1.3$ & $21.1 \pm 2.3$ & $20.3 \pm 1.0$ & $20.4 \pm 1.2$ \\
L5 & $17.5 \pm 1.4^{*}$ & $20.6 \pm 0.6^{*}$ & $17.0 \pm 0.8^{*}$ & $21.6 \pm 1.9^{*}$ & $15.3 \pm 1.5^{*}$ & $19.5 \pm 1.0^{*}$ \\
\hline
\end{tabular}

$* \mathrm{p}<0.05$ denotes the significance of mean between different groups on the same line. 


\section{DISCUSSION}

Many studies on weightlifters have been carried out so far. Biomechanical studies on elite weightlifters, the kinetic values showing the pressure exerted by the body and the weightlifting bars on the surface in the phases of weight-lifting, the angular and linear kinematics whereby the articulation angle and the bar orbit were checked and the calculations of force and energy exerted on the bar were under focus during the study (Gourgoulis et al., 2002; Isaka et al., 1996; Stone et al., 1998; Schilling et al., 2002; Souza et al., 2002).

Eckstein et al. (2006), in a cross-sectional design, compared the acute effects of different knee movements in the studies they carried out on the weightlifters and sedentary individuals in 2006. However, no studies were encountered either on the detailed analysis of the 3D columna vertebralis images taken by CT devices of elite weightlifters or on 3D reconstruction of these images. Considering the statistical results of the columna vertebrali, statistically significant differences $(p<0.05)$ only between the vertebrae L3 and L5 in the length of pars lumbalis were observed in the elite weight-lifters and sedentary individuals. L3 vertebra was measured as $21.8 \pm 0.4 \mathrm{~mm}$ in the elite weight-lifters while that of the sedentary individuals was measured as $20.2 \pm 0.6 \mathrm{~mm}$. The growth in the vertebra L3 in the elite weight-lifters suggests that there exists more pressure exerted on the bone of weight-lifters than that of the sedentary individuals. His suggestion is thought to be supported by Pettersson et al. (1998) who reported that there existed a growth in the muscle power and bone parameters in individuals who do sports and exercises. Kalayci (2008) reports that the biometric proportions of metacarpal and phalangeal bones of the judoists are statistically greater than those of sedentary individuals in the studies he carried out on both groups. We have observed a similar proliferation in the bones of weightlifters, in L3 segment. While the L5 segment was measured as $19.9 \pm 1.0 \mathrm{~mm}$ in the elite weightlifters, that of the sedentary individuals amounted to $20.9 \pm 0.4$, which was statistically a significant difference $(p<0.05)$. The decrease in L5 segment of the elite weight-lifters reveals a deformation in the vertebra, which suggests that excessive weightlifting might lead to a deformation in the bones.

Considering the statistical results of the canalis vertebralis, statistically significant differences $(\mathrm{p}<0.05)$ between the elite weight-lifters and sedentary individuals were reported in the volume of pars cervicalis, on the surface area of the $\mathrm{C} 7$ segment, in the length of C5, C6 and C7 segments. Statistically significant differences $(\mathrm{p}<0.05)$ in $\mathrm{T} 4, \mathrm{~T} 7$ and $\mathrm{T} 8$ segments and in the volume of pars thoracalis and in the length of T2, T7 and T8 were reported. Furthermore, statistically significant differences $(\mathrm{p}<0.05)$ in L3 and L5 segments, in the volume of Pars lumbalis, on the surface area of L5 segment and in the length of L2, L3 and L5 segments were noted. The fact that the biometric measurements of $\mathrm{C} 7$ segment in the pars cervicalis of the elite weight-lifters, that T7 and T8 segments of the pars thoracalis of the elite weight-lifters are lower than those of the sedentary individuals suggests that there exists a deformation in these parts. In addition, the values in pars lumbalis in L2 and L3 segments in terms of surface area and in L3 segment in terms of length were reported to be lower in the elite weightlifters than the sedentary individuals. However, the biometric measurements in L5 segments of the sedentary individuals were found to be higher than those of the elite weightlifters.

Considering all the biometric measurements, in comparison to the sedentary weightlifters, a significant deformation in only L5 segment of columna vertebralis and canalis vertebralis was encountered in the weightlifters $(\mathrm{p}<0.05)$.

The biometric measurements and 3D images of columna vertebralis in both elite weightlifters and other elite athletes are thought to make a positive contribution to the appropriate therapeutic approaches adopted by orthopedists and neurologist, making the diagnosis and treatment of bone-related or the relevant channelrelated pathological formations (vertebral exostosis, vertebral channel stenosis, vertebral channel tumor, intervertebral hernia etc.) easier. In light of the 3D vertebral data of the sedentary individuals, it will be possible to develop full-scale vertebral channel models. Moreover, both the method employed during the study and the fact that the data obtained from this method constitute the basis for prospective anatomical studies and help students taking anatomy courses gain a modern understanding of training and point of view is an undeniable fact. In addition, it is expected that the computed data produced during this study will constitute a scientific basis for the morphological comparison of columna vertebralis of both elite athletes and sedentary individuals, thereby making an important contribution to the field of sports medicine. 
INCE, A. \& EKEN, E. Reconstrucción tridimensional de imágenes de columna vertebral de pesistas de elite por tomografía computadorizada multidetectora. Int. J. Morphol., 32(4):1184-1189, 2014.

RESUMEN: El objetivo fue realizar un estudio comparativo de la estructura vertebral de pesistas de elite y un grupo sedentario (grupo control) através de la obtención de datos y modelos tridimensionales mediante fotogrametría de secciones de la columna vertebral por TCMD. La columna vertebral de los pesistas, 8 varones y 8 sujetos sedentarios (grupo control) fue escaneada con un dispositivo para diagnóstico de alta definición TCMD. Los hallazgos demográficos sugieren que no hay diferencias entre los pesistas y los sujetos sedentarios. Las imágenes axiales 2D en formato DICOM fueron grabados en CD y luego copiadas a un PC en 3D-Doctor 4.0, un programa de modelado 3D que ya se había instalado. La reconstrucción se llevó a cabo con el componente de representación 3D del programa. Todos los datos fueron medidos por el programa de manera automática y los análisis estadísticos fueron determinados mediante una prueba t por SPSS 15.0. Considerando los resultados estadísticos de la columna vertebral, solamente en la longitud de la parte lumbar se observaron algunas diferencias consideradas significativas ( $\mathrm{p}<0,05)$ entre las vértebras L3-L5 en los pesistas de elite y los sujetos sedentarios. Por lo tanto, estas técnicas y los procedimientos de reconstrucción en tres dimensiones deben ser puestos en práctica en la medicina deportiva, debido a que este tipo de estudio puede ser útil en los trabajos de subestructura que se realizen en los pesistas mediante TCMD.

PALABRAS CLAVE: Columna vertebral; Reconstrucción tridimensional; Pesistas de elite; Tomografía computadorizada.

\section{REFERENCES}

Bazille, A.; Guttman, M. A.; McVeigh, E. R. \& Zerhouni, E. A. Impact of semiautomated versus manual image segmentation errors on myocardial strain calculation by magnetic resonance tagging. Invest. Radiol., 29(4):427-33, 1994.

Eckstein, F.; Hudelmaier, M. \& Putz, R. The effects of exercise on human articular cartilage. J. Anat., 208(4):491-512, 2006.

Gourgoulis, V.; Aggeloussis, N.; Antoniou, P.; Chritoforidis, C.; Mavromatis, G. \& Garas, A. Comparative 3-dimensional kinematic analysis of the snatch technique in elite male and female greek weightlifters. J. Strength Cond. Res., 16(3):359-66, 2002.

Hall, R. K. The role of CT, MRI and 3D imaging in the diagnosis of temporomandibular joint and other orofacial disorders in children. Aust. Orthod. J., 13(2):86-94, 1994.

Harbili, E. \& Aritan, S. Comparative biomechanical analysis of the snatch technique in elite weightlifters. Hacettepe J. Sport Sci., 16(3):124-34, 2005.

Hoek van Dijke, G. A.; Snijders, C. J.; Stoeckart, R. \& Stam, H. J. A biomechanical model on muscle forces in the transfer of spinal load to the pelvis and legs. J. Biomech., 32(9):927-33, 1999.

Hu, H.; He, H. D.; Foley, W. D. \& Fox, S. H. Four multidetector-row helical CT: image quality and volume coverage speed. Radiology, 215(1):55-62, 2000.

Isaka, T.; Okada, J. \& Funato, K. Kinematic analysis of the barbell during the snatch movement of elite asian weight lifters. J. Appl. Biomech., 12(4):508-16, 1996.

Kalayci, I. 3D Reconstruction of Phalangeal and Metacarpal Bones of Male Judo Players and Sedentary Men by MDCT Images. J. Sports Sci. Med., 7(4):544-8, 2008

Kalra, M. K.; Maher, M. M.; Toth, T. L.; Hamberg, L. M.; Blake, M. A.; Shepard, J. A. \& Saini, S. Strategies for CT radiation dose optimization. Radiology, 230(3):619-28, 2004.
Krupa, P.; Krsek, P.; Cernochova, P. \& Molitor, M. 3D real modelling and CT biomodels application in facial surgery. In: European Society of Neuroradiology. Neuroradiology. Berlin, Springer Verlag, 2004. pp.141.

Marchocka, M. \& Smuk, E. Analysis of body build of senior weightlifters with particular regard for proportions. Biol. Sport, 1(1):55-71, 1984

Pettersson, U.; Alfredson, H.; Nordström, P.; Henriksson-Larsén, K. \& Lorentzon, R. Bone mass in female cross-country skiers: relationship between muscle strength and different BMD sites. Calcif. Tissue Int., 67(3):199-206, 2000.

Prokop, M. General principles of MDCT. Eur. J. Radiol., 45(Suppl. 1):S4-10, 2003.

Schilling, B. K.; Stone, M. H.; O’Bryant, H. S.; Fry, A. C.; Coglianese, R. H. \& Pierce, K. C. Snatch technique of collegiate national level weightlifters. J. Strength Cond. Res., 16(4):551-5, 2002.

Souza, A. L.; Shimada, S. D. \& Koontz, A. Ground reaction forces during the power clean. J. Strength Cond. Res., 16(3):423-7, 2002.

Stone, M. H.; O'Braynt, H. S.; Williams, F. E. \& Johnson, R. L. Analysis of bar paths during the snatch in elite male weightlifters. Nat. Strength Cond. Assoc., 20:30-38, 1998.

\section{Correspondence to: \\ Alparslan I'nce, PhD \\ Ordu University \\ Physical Education And Sport In Schools \\ Cumhuriyet Yerles, kesi Cumhuriyet Mahallesi Merkez \\ Ordu \\ TURKEY}

Email: ftrbesyo@hotmail.com

Received: 24-02-2014

Accepted: 12-07-2014 